International Journal of Multidisciplinary Studies and Innovative Research

Publisher: Catholic University College of Ghana

ISSN: 2737-7172 (0), ISSN: 2737-7180 (P)

DOI:10.53075/ijmsirq54216

DOI Url: http://doi.org/10.53075/ijmsirq54216

\title{
THE ANTITHETICAL EFFECT OF CYBERCRIME ON SMALL MEDIUM ENTERPRISE SMES: PUBLIC ASSESSMENT
}

\author{
Atianashie Miracle A. ${ }^{1}$, Elisha D'Archimedes Armah' ${ }^{3}$, Nasiru Mohammed ${ }^{2}$ \& Sylvana Sackey-Sam² \\ 1 Department of Computer Science, Catholic University College of Ghana \\ miracleatianashie81@gmail.com \\ 2Department of Artificial Intelligence, Beijing University of Civil Engineering and Architecture \\ ${ }^{3}$ Cape Coast Technical University Ghana \\ Copyrights \\ Copyright for this article is retained by the author, with first publication rights granted to the journal. This is an open-access article \\ distributed under the terms and conditions of the Creative Commons Attribution license (http://creativecommons.org/licenses/by/4.0/)
}

Received: October 19, 2021

Accepted: November 14, 2021

Published Online: November 17, 2021

\begin{abstract}
Notwithstanding the emergent indications and fears about the effect of cybercrime, only a few speculative studies have explored the topic to complement those published by consultancy firms, cybersecurity companies, and private institutions. The review of all these studies shows that there is no consensus on how to delineate and measure cybercrime or its effect on Small and Medium Scale Enterprises. Against this background, this research paper had four objectives namely to: determine the effect of Cybercrime on Small and Medium Scale Businesses; identify the real cost of Cybercrime to Ghana SMEs; identify the reasons for the increase of cybercrimes in Ghana SMEs and; identify the causes of cybercrime in Ghana SMEs. A cross sectional study is used to assess the burden of cost or IT needs of a population and are particularly useful in informing the planning and allocation of IT resources. The study consists of forty-nine (49) participants. The target population is small and medium enterprises in Ghana. Simple random sampling was use to recruit and select the study respondents. As the name implies, simple random sampling means that, in this case, small and medium enterprises in Ghana will be chosen entirely by chance, and each of these enterprises in Ghana has an equal chance or probability of being selected. Furthermore, eight small and medium enterprises in Ghana were involved. And these SMEs include businesses that buy and sell, transportation companies, etc. The findings of the research confirmed the assumptions put forward, since there were statistically significant variations in the proportion of people who participated in cybercrime activities based on their age and the size of the business in which they worked.
\end{abstract}

Keywords: Cybercrime, SMEs, Security, Ghana.

\section{INTRODUCTION}

Information systems security is the critical issue and major concern for any enterprise regardless of size, shape or industry. Security breaches cause huge financial loss to an organization particularly in Small and Medium Scale Enterprises (SMEs). (Bada \& Nurse, 2019). The threats against SMEs are increasing at an alarming rate and most of the times the crimes remain invisible and criminals are not prosecuted reference. (Praveen et al., 2017). According to (Zec, 2015, Small and Medium Scale Enterprises (SMEs) are defined as businesses whose personnel numbers fall below certain limits. (Bada \& Nurse, 2019). The abbreviation "SME" is used by international organizations such as the World Bank, the European Union, the United Nations and the World Trade Organization. The SMEs must be safe for both sellers and buyers because they play a very important role in the economy of many countries and so the threats and attacks against the SMEs can impact negatively on the economies of many countries. (Apau et al., 2019). Majority of SMEs are in trouble because of the continual increase in cost of cybercrimes. In Ghana about $97 \%$ of the businesses are SMEs and they account for more than quarter of the country annual GDP. (Veluthakal \& Thurmond, 2021). Therefore, the vulnerabilities to SMEs due to cybercrimes seriously affect the economy and very crucial to the country's overall security, which needs to be addressed immediately. 
International Journal of Multidisciplinary Studies and Innovative Research

Publisher: Catholic University College of Ghana

ISSN: $2737-7172(0)$, ISSN: 2737-7180 (P)

DOI:10.53075/ijmsirq54216

DOI Url: http://doi.org/10.53075/ijmsirq54216

Globally, the web and the Internet provide an essential medium for Small and Medium Scale Enterprises (SMEs) and offer a lot of opportunities to both SMEs and the large scale industries (Apau et al., 2019). Since there are differences in the nature of market operations and resource strengths, the adoption and integration paths of technologies into SMEs also differ (smith, 2011). The adoption of technology by SMEs is speedily increasing and this has opened avenues for cyber-crime activities (Nakashima et al., 2010). The technologies and the associated businesses of SMEs are growing due to the rapidly evolving Internet users across the globe (European Commission \& Commissie, 2017).

Internet and computer technology makes life easy and fast but also in danger because of the threat from the deadliest type of criminality termed as Cybercrime. This means computers and computer networks act as a tool, a target or a place of cybercrimes (Fishbein and Ajzen, 2020). There is no generally agreed definition for Cybercrime. Cybercrimes are considered as those activities with the use of computers to steal or retrieve information stored online or from another database or damage of data and equipment through trespassing in to others network and computer (Cohen, et al., 2016). Cyber risk ranked third by Lloyd's Digital Risk Index in 2013 when considering the largest risk facing the global business. As per the recent survey by Marsh \& McLennan Companies cyber risk, became the second largest emerging threat affecting Ghana Small and medium scale enterprises (SMEs) within two years (Praveen et al., 2017) Most of the SMEs do not have robust security measures against cyber threats and these criminals are attracted towards the small businesses. This is a major reason for majority of small business failures (Moura \& Serrão, 2018). According to (Apau et al., 2019) the annual cost to the global economy from cybercrime is estimated to be more than $\$ 400$ billion, which is equal to more than the national income of most countries and governments. It cost Ghana 463 million dollars in 2012 due to cybercrime and the major reason for it was poor security practices in most organizations (Apau et al., 2019) Lack of training and knowledge on cybercrimes, spending more on other business matters and less on IT security and using old version of systems without updating were considered some of the major reasons for rise in cybercrime in Ghana (Bertino \& Ferrari, 1998).

Ghana has witnessed increased usage of Internet over some time now. Internet users in Ghana reached two million in 2011 (PWC, 2017) and over 10 million in 2014 (Amrin et al., 2014). Extensive use of the Internet affects ecommerce businesses (Bada \& Nurse, 2019). In using the internet for business transaction, trust is considered important and significant indicator (Hayes et al., 2012). According to Hawkins, et al. (Hadlington, 2018), the openness of the Internet medium allows everyone access, creating an open medium for cyber-crime activities. Internationally, cyber-crime and other criminal activities are on the rise. It is believed that most of these activities originate from West Africa, particularly Nigeria, attributing the increasing cyber-crime activities to the inability of security agencies to have the necessary legal framework to deal with perpetrators. This could be due to the diverging views on the prosecution of cyber criminals.(Okofo-Dartey \& Kwenda, 2021) The major challenge has been the application of the law of jurisdiction (Chaudhari \& Srivastava, 2017). Currently, there are major debates about how cybercrime perpetrators should be punished. Whereas some school of thought believed it should be the country where the internet service provider is located, others think it should be according to the laws of the country where the website is located with others also advocating for the person to be punished according to the laws of the country where the crime was committed. (Mekawie \& Yehia, 2021)

Although some of these studies acknowledge the different dimensions of trust, most of them have adopted either customer trust in vendors or trust in Internet. Thus, research that integrates the two dimensions of trust is scarce. Other studies have also predominantly examined SMEs activities either focusing on specific vendors or from an institutional perspective. Currently, research that discusses country specific cybercrime perception and its influences on purchase intention is scarce. This paper extends the Theory of Reasoned Action (TRA) proposed by (Bada \& Nurse, 2019). This study sought to address the impact of Cybercrime on Small and Medium Scale Businesses, cost of Cybercrime to Ghana SMEs and reasons for the increase in cybercrimes in Ghana SMEs. We adopted TRA because it is one of the most used theories in the field of Cybercrimes on Business. 
International Journal of Multidisciplinary Studies and Innovative Research

Publisher: Catholic University College of Ghana

ISSN: $2737-7172(0)$, ISSN: 2737-7180 (P)

DOI:10.53075/ijmsirq54216

DOI Url: http://doi.org/10.53075/ijmsirq54216

The objectives of the research were to: explore the effect of Cybercrime on Small and Medium Scale Businesses; identify the real cost of Cybercrime to Ghana SMEs; identify the reasons for the increase of cybercrimes in Ghana SMEs, and identify the causes of cybercrime in Ghana SMEs.

\section{MATERIALS AND METHODS}

\section{Study Design and Type}

The study will be a cross sectional study. A cross sectional study is used to assess the burden of cost or IT needs of a population and are particularly useful in informing the planning and allocation of IT resources. A cross sectional survey may be purely descriptive and used to assess the burden of a particular cost in a defined population. This research used the cross-sectional survey strategy and it aided in answering the research questions by collecting substantial amount of information using questionnaires that were administered. Descriptive research will be used to establish accurate descriptions of variables without demonstrating the existence of relationship between variables. According to Cooper and Schindler (2003), descriptive research is concerned with finding out what, where and how of a phenomenon. Descriptive research was chosen because it enables the study to generalize the findings to the entire population.

\section{Study Population}

The study consists of forty-nine (49) participants. The target population is small and medium enterprises in Ghana

\section{Sampling Technique and Sample Size}

Simple random sampling was use to recruit and select the study respondents. As the name implies, simple random sampling means that, in this case, small and medium enterprises in Ghana will be chosen entirely by chance, and each of these enterprises in Ghana has an equal chance or probability of being selected. Furthermore, eight small and medium enterprises in Ghana were involved. And these SMEs include businesses that buy and sell, transportation companies, etc.

Information Technology (IT) specialists and administrators in SMEs from Sunyani, capital of Bono region of Ghana participated in the study, which was conducted in two parts. First, the forty-nine (49) participants completed a questionnaire that asked them questions to explore the effect of Cybercrime on Small and Medium Scale Businesses, reasons for the increase inf cybercrimes in Ghana SMEs, causes of cybercrime in Ghana SMEs and the cost of Cybercrime to Ghana SMEs. Using a 5-point Likert scale, participants indicated the level of agreement with several statements that assessed confidence in their knowledge of Cybercrime on SMEs. The survey also asked participants about their level of computer usage as well as measures they have taken to address computer security threats in their businesses.

In the second part of the study, the IT specialists and administrators in the SMEs were interviewed based on the major causes of cybercrime in Ghana SMEs, effects of Cybercrime on SMEs, cost of Cybercrime to Ghana SMEs and the reasons for the increase in cybercrimes in Ghana SMEs. The data were analyzed using SPSS Version 19.0. We also generated a summated score, which we could then compare with their score on the portion of the test that assessed their knowledge of cybercrimes in Ghana SMEs. Demographic variables, which consist of age and company size were gathered to more fully, understand the environment within which these SMEs operate.

\section{RESULTS}

Age of participants and size of SMEs used for the study 
International Journal of Multidisciplinary Studies and Innovative Research

Publisher: Catholic University College of Ghana

ISSN: $2737-7172(0)$, ISSN: 2737-7180 (P)

DOI:10.53075/ijmsirq54216

DOI Url: http://doi.org/10.53075/ijmsirq54216

The age and size of SMEs are in Tables 1 and 2.

Table 1.

\begin{tabular}{|l|c|c|c|c|c|}
\hline \multicolumn{2}{|c|}{ Variables } & Frequency & Percent & Valid Percent & Cumulative Percent \\
\hline \multirow{3}{*}{ Age } & $18-24$ & 21 & 42.9 & 42.9 & 42.9 \\
\cline { 2 - 6 } & $35-64$ & 28 & 57.1 & 57.1 & 100.0 \\
\cline { 2 - 6 } & Total & $\mathbf{4 9}$ & $\mathbf{1 0 0 . 0}$ & $\mathbf{1 0 0 . 0}$ & - \\
\hline
\end{tabular}

Source: Field survey, 2021

From Table 1, forty-nine IT specialists and administrators participated in the study. Of those participants, 21(42.9\%) were age 18-24 years while 28 (57.10\%) were aged between 35-64 years. Age of respondents is an important factor in the consideration of one's perception.

Table 2. Size of the employees of SMEs used for the study

\begin{tabular}{|l|c|c|c|c|c|}
\hline \multicolumn{2}{|c|}{ Variables } & Frequency & Percent & Valid Percent & $\begin{array}{c}\text { Cumulative } \\
\text { Percent }\end{array}$ \\
\hline Valid & 10 or less & 15 & 30.6 & 30.6 & 30.6 \\
\cline { 2 - 6 } & $11-50$ & 23 & 46.9 & 46.9 & 77.6 \\
\cline { 2 - 6 } & $51-250$ & 6 & 12.2 & 12.2 & 89.8 \\
\cline { 2 - 6 } & $250+$ & 5 & 10.2 & 10.2 & 100.0 \\
\cline { 2 - 6 } & Total & $\mathbf{4 9}$ & $\mathbf{1 0 0 . 0}$ & $\mathbf{1 0 0 . 0}$ & \\
\hline
\end{tabular}

Source: Field survey, 2021

From Table 2, 15 participants (30.6\%) were from SMES with 10 or less employees, while 23 (46.9\%) had 11-50 employees; 6 (12.2\%) had 51-250 employees, and 5 (10.2\%) had more than 250 employees. This is an indication that many IT specialists and administrators are employed by SMEs that employ 11 to 50 staff.

\section{Effect of cybercrime on SMEs}

Table 3. Percent responses on the effect of Cybercrime on SMEs

\begin{tabular}{|l|c|c|c|c|c|}
\hline \multicolumn{1}{|c|}{ Item } & $\begin{array}{c}\text { Strongly } \\
\text { Agree }\end{array}$ & Agree & Undecided & Disagree & $\begin{array}{c}\text { Strongly } \\
\text { Disagree }\end{array}$ \\
\hline Cyber Fear in Teenager & 24.5 & 32.7 & 22.4 & 12.2 & 8.2 \\
\hline Damage Reputations & 26.5 & 22.4 & 8.2 & 18.4 & 24.5 \\
\hline Wasted Time & 12.2 & 32.7 & 34.7 & 10.2 & 8.2 \\
\hline The Cost of Protection & 24.5 & 32.7 & 22.4 & 12.2 & 8.2 \\
\hline Changing Methods of Doing Business & 22.4 & 24.5 & 22.4 & 18.4 & 12.2 \\
\hline Loss of Sales & 28.6 & 22.4 & 22.4 & 18.4 & 8.2 \\
\hline Piracy and Identity Theft & 16.3 & 18.4 & 30.6 & 18.4 & 16.3 \\
\hline Loss of Revenue & 26.5 & 30.6 & 22.4 & 14.3 & 6.1 \\
\hline Reduce Productivity & 30.6 & 34.7 & 14.3 & 14.3 & 6.1 \\
\hline
\end{tabular}

Source: Field survey, 2021

According to Table 3, in the response to Cyber Fear in Teenagers, 24.5 percent strongly agree, 32.7 percent Agree, 22.4 percent Undecided, 12.2 percent Disagree, and 8.2 percent strongly Disagree were the results. Concerning the second item, Damage Reputations, 26.5 percent strongly agree, while 22.4 percent agree, 8.2 percent were undecided, 18.4 percent disagreed and 24.5 percent strongly disagreed; 8.2 percent were undecided. Wasted Time 
International Journal of Multidisciplinary Studies and Innovative Research

Publisher: Catholic University College of Ghana

ISSN: $2737-7172(0)$, ISSN: 2737-7180 (P)

DOI:10.53075/ijmsirq54216

DOI Url: http://doi.org/10.53075/ijmsirq54216

is the third point on the list. The percentage of people who strongly agree is 12.2 percent. The percentage of people who agree is 32.7 percent. The percentage of people who disagree is 10.2 percent. Among those who strongly agree with the fourth item on the list, The Cost of Protection, 24.5 percent are highly in agreement, 32.7 percent are in agreement, 22.4 percent are undecided, 12.2 percent are disagree, and 8.2 percent are severely disagree. In the fifth item, Changing Methods of Doing Business, 22.4 percent strongly agree, 24.5 percent agree, 22.4 percent are undecided, 18.4 percent disagree, and 12.2 percent strongly disagree. In the fourth item, Changing Methods of Doing Business, 22.4 percent strongly agree, 24.5 percent agree, 22.4 percent disagree, 22.4 percent undecided, 18.4 percent disagree, and 12.2 percent strongly disagree. Sixth, when it comes to the loss of sales issue, 28.6 percent highly agree with the statement, 22.4 percent agree, 22.4 percent are undecided, 18.4 percent disapprove, and 16.3 percent severely disapprove of it. Among those who firmly agree on the seventh item, piracy and identity theft, 16.3 percent are highly in agreement with it, while 18.4 percent are in agreement. Undecided respondents comprised 30.6 percent, while 18.4 percent were in disapproval and 16.3 percent strongly disapprove of it. In the eight items, 26.5 percent strongly agree, 30.6 percent agree, 22.4 percent are undecided, 14.3 percent disagree, and 6.1 percent strongly disagree. In the item Loss of Revenue, 26.5 percent strongly agree, 30.6 percent agree, 22.4 percent undecided, 14.3 percent disagree, and 6.1 percent strongly disagree. As an example, in the ninth question, Reduce Productivity, 30.6 percent strongly agree with the statement while 34.7 percentage agree. In addition, 14.3 percent were undecided while 14.3 percentage disagreed and 6.1 percent strongly disagreed with the statement.

\section{Cost of Cybercrime on SMEs}

Table 4. Percent responses on the cost of Cybercrime on SMEs

\begin{tabular}{|l|c|c|c|c|c|}
\hline \multicolumn{1}{|c|}{ Item } & $\begin{array}{l}\text { Strongly } \\
\text { Agree }\end{array}$ & Agree & Undecided & Disagree & $\begin{array}{c}\text { Strongly } \\
\text { Disagree }\end{array}$ \\
\hline $\begin{array}{l}\text { Cybercrime is estimated 1 or more } \\
\text { trillion in Ghana }\end{array}$ & 16.3 & 36.7 & 22.4 & 16.3 & 8.2 \\
\hline Indirect Losses & 12.2 & 24.5 & 36.7 & 18.4 & 8.2 \\
\hline Defence costs & 20.4 & 28.6 & 24.5 & 16.3 & 10.2 \\
\hline Direct losses & 12.2 & 42.9 & 8.2 & 24.5 & 12.2 \\
\hline
\end{tabular}

Source of filed 2021

According to Table 4, 16.3 percent highly agree, 36.7 percent agree, 22.4 percent are undecided, 16.3 percent disagree, and 8.2 percent strongly disagree with the estimate of one or more trillion dollars in international cybercrime. When it comes to Indirect Losses, $12.2 \%$ of those polled highly agreed, $24.5 \%$ agreed, $36.7 \%$ were undecided, $18.4 \%$ disagreed, and $8.2 \%$ strongly disagreed with the statement. 20.4 percent strongly agree, 28.6 percent agree, 24.5 percent are undecided, 16.3 percent disapprove, and 10.2 percent severely disapprove of defense expenses in the third item. In the fourth category, direct losses accounted for $12.2 \%$ of the total, with $42.9 \%$ agreeing, $8.2 \%$ disagreeing, $24.5 \%$ disagreeing, and $12.2 \%$ severely disagreeing.

Reasons for the Increase in Cybercrime in SMEs

Table 5. Percent reasons for the increase in Cybercrimes in Ghana SMES

\begin{tabular}{|l|c|c|c|c|c|}
\hline \multicolumn{1}{|c|}{ Item } & $\begin{array}{l}\text { Strongly } \\
\text { Agree }\end{array}$ & Agree & Undecided & Disagree & $\begin{array}{c}\text { Strongly } \\
\text { Disagree }\end{array}$ \\
\hline $\begin{array}{l}\text { Weak security controls in the } \\
\text { corporate cloud. }\end{array}$ & 18.4 & 55.1 & 12.2 & 6.1 & 6.1 \\
\hline $\begin{array}{l}\text { Servers that are left unattended or } \\
\text { are not updated }\end{array}$ & 18.4 & 59.2 & 10.2 & 12.2 & 8.2 \\
\hline $\begin{array}{l}\text { Known vulnerabilities are not } \\
\text { patched in time }\end{array}$ & 4.1 & 40.8 & 30.6 & 18.4 & 6.1 \\
\hline
\end{tabular}


International Journal of Multidisciplinary Studies and Innovative Research

Publisher: Catholic University College of Ghana

ISSN: $2737-7172(0)$, ISSN: $2737-7180(\mathrm{P})$

DOI:10.53075/ijmsirq54216

DOI Url: http://doi.org/10.53075/ijmsirq54216

\begin{tabular}{|l|c|c|c|c|c|}
\hline Criminals sell stolen information & 24.5 & 42.9 & 16.3 & 8.2 & 8.2 \\
\hline
\end{tabular}

Source of filed 2021

From Table 5, the answer to the question of "weak security controls in the corporate cloud" were provided. 18.4 percent highly agree, with 55.1 percent agreeing, 12.2 percent undecided, 6.1 percent disagreeing, and 6.1 percent strongly disagreeing with the survey results. The second item, servers that are left unattended or are not updated, received strong agreement from 18.4 percent of respondents, 59.2 percent of respondents agreed, 10.2 percent were undecided, 12.2 percent dissented, and 8.2 percent strongly disagreed. The third point is that known vulnerabilities are not fixed in a timely manner. 4.1 percent highly agree, with 40.8 percent agreeing, 30.6 percent undecided, 18.4 percent disagreeing, and 6.1 percent strongly disagreeing; the rest are divided. Among those who strongly agree with the fourth item (Criminals sell stolen information) are 24.5 percent of those who strongly agree, 42.9 percent of those who strongly agree are also undecided, 16.3 percent are undecided, 8.2 percent disagree and 8.2 percent strongly disagree.

\section{Causes of Cybercrime in SMEs}

Table 6. Causes of Cybercrime in Ghana SMES

\begin{tabular}{|l|l|l|l|l|l|}
\hline \multicolumn{1}{|c|}{ Item } & $\begin{array}{c}\text { Strongly } \\
\text { Agree }\end{array}$ & Agree & Undecided & Disagree & $\begin{array}{l}\text { Strongly } \\
\text { Disagree }\end{array}$ \\
\hline The Sake of Recognition & 42.9 & 20.4 & 28.6 & 6.1 & 2.0 \\
\hline Make Quick Money & 30.6 & 14.3 & 26.5 & 18.4 & 10.2 \\
\hline Revenge & 30.6 & 38.8 & 14.3 & 8.2 & 8.2 \\
\hline Alleviate Boredom & 42.9 & 22.4 & 12.2 & 14.3 & 8.2 \\
\hline
\end{tabular}

Source of filed 2021

Table 6 depicts the audience's response to For the Sake of Recognition. 42.9 percent strongly agree, compared to 20.4 percent who agree, 28.6 percent who are undecided, 6.1 percent who disagree, and 2.0 percent who strongly disagree with the statement. Make Quick Money is the second item on the list. 30.6 percent strongly agree, 14.3 percent agree, 26.5 percent are undecided, 18.4 percent disagree, and 10.2 percent strongly disagree, according to the poll. Regarding the third item, Revenge, 30.6 percent strongly agrees, while 38.8 percent agree, 14.3 percent were undecided, 8.2 percent disagreed, and 8.2 percent strongly disagreed. In the fourth item, Revenge, 30.6 percent strongly agrees while 38.8 percent agree. 42.9 percent highly agree with the fourth item, Alleviate Boredom; 22.4 percent agree; 12.2 percent are undecided; 14.3 percent disagree; and 8.2 percent strongly disagree with the fourth item, Alleviate Boredom.

\section{DISCUSSION}

The present study aimed to provide experiential evidence on how age, individual differences in attitudes towards the effect of cybercrime on small-medium enterprise SMEs, and company size impact on the cybercrime posture of an organization. The results supported the hypotheses for the study, as there were significant differences according to both age and company size on cybercrime behaviors. The difference in attitudes towards cybercrime according to age groups is an interesting result, with individuals in the higher age bracket demonstrating a more positive attitude towards cybercrime. A potential reason for this could be linked to the personality trait of conscientiousness, associated with the propensity to follow rules and norms that are set by society. (Houghton et al., 2020) The trait is also linked to planning, delay in gratification, and the ability to control impulses, and has been shown to increase with age. (Houghton et al., 2020) It could be that those individuals in the higher age bracket are more conscientious and see engaging in good cybersecurity practices as being an essential part of their working life.

Significant differences in cybercrime behaviors and attitudes towards cybersecurity concerning the size of the company for which the individual was working were also noted. It is interesting to note that those working with companies with 250 or more employees had the highest level of engagement in risky cybercrimes behaviors. Again, 
International Journal of Multidisciplinary Studies and Innovative Research

Publisher: Catholic University College of Ghana

ISSN: $2737-7172(0)$, ISSN: 2737-7180 (P)

DOI:10.53075/ijmsirq54216

DOI Url: http://doi.org/10.53075/ijmsirq54216

without engaging in further research the reasons for such a difference remain unclear. On the one hand, it may be that larger organizations have better communication systems or effective cybersecurity measures due to larger budgets. (Hadlington, 2018).

We are living in a digital world where everything has now been taken to the internet. Whether it is storing data or getting access to information, we seek assistance from the internet to get things done. Our growing involvement in the cyber world makes us prone to cyber threats. A computer is known to store an enormous amount of data in a compact space, and that's one of the biggest reasons behind cyber-attacks. It was only after the discovery of computers that cybercrime came into existence. Storing data in a small space makes it easier for hackers to steal data in no time and utilize it for their own profit. Hence, it is advised not to store all the necessary data on the system and to segregate it in different places. It is often difficult or impossible to safeguard a system from data breaches that involve complex technologies. Security can only be compromised when the system is easy to access for hackers. Skilled hackers can get unauthorized access by breaching access codes, retina images, voice recognition, etc. They can easily fool the biometric system and pass through the firewall of the system. Operating systems make computers functional, and these operating systems are created with millions of codes. Operating systems are programmed by developers who are humans, thereby making the codes vulnerable to errors. Though the slightest loop in the codes might not make a big difference in the functions of the operating system, these gaps can be easily exploited by cybercriminals. They can slip in through these loopholes and make the operating system malicious for the users. Complex coding is frequently the root cause of cybercrime. Anything that we neglect and consider easy to ignore can turn into a grave concern. Cybercrime works the same way. Negligence in ensuring the security of your system can bring you big trouble. A little negligence on your end can provide a welcoming aisle for cybercriminals. Hence, it is necessary to remain vigilant about the happenings in your system. The reasons listed above are just a few of the important reasons for cybercrime that you should be aware of in order to protect your interests from potential threats.

Despite the rise in cybercrime among small-medium enterprise SMEs, many small businesses remain susceptible to cyber-attacks due to lack of resources and surprisingly, a lack of knowledge of the threat. (Chaudhari \& Srivastava, 2017) found that despite the increasing threats posed by cyberattacks, an astounding one in four small business owners has little no understanding of the issue whatsoever. Dr. David Kwame, the Chief Operating Officer of the Ghana National Cybersecurity noted in testimony to the House Committee on SMEs that "small-medium enterprise, also known as SMEs are challenged both by the ability and the desire to secure themselves against cyber threats which makes them uniquely vulnerable to cyber-attacks. Fifty percent of SMEs have been the victims of cyber-attack and over 60 percent of those attacked go out of business. Often SMEs do not even know they have been attacked until it is too late." You are to discuss the findings of the study in relation to other studies done in the past. How does cybercrime impact on the operations of SMEs?

\section{CONCLUSION}

Currently, the speed at which cybercrime is increasing is one of the top disturbing facts in the world of business. The impact of cybercrime can be visualized in all fields of the economy. The elevation in the number of cybercrimes shows that it is almost impossible for law enforcement agencies and IT specialists to eliminate its effects. It is mainly due to the high level of technical knowledge of the cyber criminals and the use of different and the most advanced tools and technologies. The cost associated with cybercrimes also increases every year in the business operations of SMEs. The Internet provides a clear channel for cybercriminals and it helps them to exploit the target for financial gain with minimum risk. Therefore, it is very relevant to conduct detailed research on the effect of cybercrimes, the causes, costs and motivating factors influencing the increase in the number of cybercrimes on SMEs particularly in Ghana. It is imperative that SMEs in Ghana invest in technologies that can mitigate cybercrimes in their businesses.

\section{ACKNOWLEDGMENT}

We grateful to Sunday Victoria for proof reading the manuscript and making further suggestion to improve its quality. 
International Journal of Multidisciplinary Studies and Innovative Research

Publisher: Catholic University College of Ghana

ISSN: $2737-7172(0)$, ISSN: $2737-7180(P)$

DOI:10.53075/ijmsirq54216

DOI Url: http://doi.org/10.53075/ijmsirq54216

\section{REFERENCES}

Amrin, N., Hartel, P., Junger, M., \& Leijtens, A. (2014). The Impact of Cyber Security on SMEs. 1-77.

Apau, R., Koranteng, F. N., \& Gyamfi, S. A. (2019). Cyber-Crime and its Effects on E-Commerce Technologies. Journal of Information, 5(1), 39-59. https://doi.org/10.18488/journal.104.2019.51.39.59

Bada, M., \& Nurse, J. R. C. (2019). Developing cybersecurity education and awareness programmes for small- and medium-sized enterprises (SMEs). Information and Computer Security, 27(3), 393-410.

https://doi.org/10.1108/ICS-07-2018-0080

Bertino, E., \& Ferrari, E. (1998). Data security. Proceedings - International Computer Software and Applications Conference, 3, 228-237. https://doi.org/10.1109/CMPSAC.1998.716660

Chaudhari, N., \& Srivastava, S. (2017). Big data security issues and challenges. Proceeding - IEEE International Conference on Computing, Communication and Automation, ICCCA 2016, February, 60-64.

https://doi.org/10.1109/CCAA.2016.7813690

European Commission, \& Commissie, E. (2017). Country report belgium 2017. Accompanying the document "communication from the commission to the european parliament, the council, the european central bank and the eurogroup". 2017 european semester: Assessment of progress on structural reforms, preventi. Commission Staff Working Document, SWD(2017) 67 final, 69.

Hadlington, L. (2018). Employees attitude towards cyber security and risky online behaviours: An empirical assessment in the United Kingdom. International Journal of Cyber Criminology, 12(1), 269-281. https://doi.org/10.5281/zenodo.1467909

Hayes, T., Tanner, M., \& Schmidt, G. (2012). Computer security threats: small business professionals' confidence in their knowledge of common computer threats. Advances in Business Research, 3(1), 107-112.

Houghton, C., Meskell, P., Delaney, H., Smalle, M., Glenton, C., Booth, A., Chan, X. H. S., Devane, D., \& Biesty, L. M. (2020). Barriers and facilitators to healthcare workers' adherence with infection prevention and control (IPC) guidelines for respiratory infectious diseases: a rapid qualitative evidence synthesis. Cochrane Database of Systematic Reviews, 4.

Mekawie, N., \& Yehia, K. (2021). Challenges of deploying cloud computing in eHealth. Procedia Computer Science, 181(2019), 1049-1057. https://doi.org/10.1016/j.procs.2021.01.300

Moura, J., \& Serrão, C. (2018). Security and Privacy Issues of Big Data. Web Services, October 2017, 2197-2229. https://doi.org/10.4018/978-1-5225-7501-6.ch114

Nakashima, T., Tsubokura, M., Ikenaga, T., \& Doi, Y. (2010). HPC-LES for unsteady aerodynamics of a heavy duty truck in wind gust - 2nd report: Coupled analysis with vehicle motion. SAE Technical Papers. https://doi.org/10.4271/2010-01-1021

Okofo-Dartey, E., \& Kwenda, F. (2021). The Free Cash Flow Hypothesis and M \& A Transactions by Acquirers from the Markets. The Journal of Developing Areas, 55(2).

Praveen, S., Chandra, U., \& Ali, A. (2017). A Literature Review on Evolving Database. International Journal of Computer Applications, 162(9), 35-41. https://doi.org/10.5120/ijca2017913365

PWC. (2017). Redefining the security culture-a better way to protect your business. 24.

smith, smith. (2011). Impact of CyberCrime on E-commerce.pdf. Journal of Marketing Theory and Practice.

Veluthakal, R., \& Thurmond, D. C. (2021). Emerging Roles of Small GTPases in Islet $\beta$-Cell Function. Cells, 10(6), 1503.

Zec, M. (2015). Cyber security Measures in SMEs: a study of IT professionals' organizational cyber security awareness. 1-99. 